|Araştırma Makalesi / Research Article |

\title{
Ortaokul Türkçe Derslerinde Kültür Aktarımına Yönelik Uygulamalar
}

\section{Applications for Cultural Transmission in Secondary School Turkish Courses}

\section{Cafer Çarkıt ${ }^{1}$}

Anahtar Kelimeler
kültür
Türkçe dersi
öğretmen
uygulama
kaynak

\section{Keywords}

culture

Turkish course

teacher

practice

source

Başvuru Tarihi/Received 30.10.2019

Kabul Tarihi /Accepted 03.02.2020
Öz

Küreselleşmenin yoğun bir şekilde hissedilip ulusal kültürlerin baskı altında olduğu günümüzde milli kültürümüzü koruma ve gelecek kuşaklara aktarma sorumluluğumuz daha da önem kazanmaktadır. Bu anlamda Türkçe öğretmenlerine çok önemli görevler düşmektedir. Onların kültür aktarımına yönelik bakış açıları, kültür aktarımı konusunda gerçekleştirdikleri uygulamalar ve bu süreçte yararlandıkları kaynaklar belirlenmelidir. Bu anlamda bir durum tespitinin yapılması ve süreçte belirlenen sorunların gözler önüne serilerek çözüm önerilerinin sunulması büyük önem arz etmektedir. Bu çalışmada Türkçe derslerinde kültürel mirasımızın aktarımına yönelik öğretmenlerin görüşleri ve uygulamaları ele alınmıştır. Araştırma nitel araştırma modelinde bir durum çalışması olarak desenlenmiştir. Araştırmanın çalışma grubu Kayseri merkez ilçelerinde görev yapan ve farklı mesleki tecrübeye sahip on üç Türkçe öğretmenidir. Çalışmada yarı yapılandırılmış görüşme formu ile elde edilen veriler içerik analizi ile değerlendirilmiştir. Ulaşılan bulgulara göre öğretmenlerin çoğu kültür aktarımının amacını milli, manevi değerleri kazandırmak ve toplumsal uyumu kolaylaştırmak olarak ifade etmişlerdir. Drama, tarihi şahsiyetleri tanıtma, kültürel konularda metin ve şiir yazdırma, türküler ve türkülerin hikâyelerini inceleme bu anlamda en sık gerçekleştirilen sınıf içi uygulamalardır. Kitaplar ve internet kültür aktarımında öğretmenlerin en sık başvurdukları kaynaklar olarak karşımıza çıkmaktadır. Öğretmenlerin tamamı ders kitaplarını kültür aktarımı noktasında yetersiz bulmaktadır.

\section{Abstract}

In today's world where globalization is felt intensely and national cultures are under pressure, our responsibility to protect our national culture and transfer it to future generations becomes even more important. In this sense, Turkish teachers have very important duties. The perspectives on transferring culture, the practices they carry out on culture transfer and the resources they use in this process should be determined. In this sense, it is of great importance to make a case determination and to present the solutions proposed by revealing the problems identified in the process. In this study, the opinions and practices of teachers about the transfer of our cultural heritage in Turkish lessons are discussed. The research was designed as a case study in the qualitative research model. The study group of the research consists of thirteen Turkish teachers working in the central districts of Kayseri with different professional experience. The data obtained from the semi-structured interview form were evaluated with content analysis method. According to the findings, most of the teachers stated that the purpose of cultural transfer was to gain national and spiritual values and to facilitate social cohesion. Drama, introducing historical figures, writing texts and poems on cultural topics, and analyzing the stories of folk songs and folk songs are the most common practices in this sense. Books and internet are the sources that teachers use most often in the transfer of culture. All of the teachers find the textbooks insufficient for the transfer of culture.

\footnotetext{
${ }^{1}$ Gaziantep üniversitesi, Nizip Eğitim Fakültesi, Türkçe ve Sosyal Bilimler Eğitimi Bölümü, Gaziantep, TÜRKiYE; https://orcid.org/0000-0003-4126-2165
} 
Extended Abstract

\section{Introduction}

Culture is a nation's lifestyle and a way of making sense of the world. In this sense, culture is all of the material and moral values of a nation. Culture is a broad spectrum that covers the genetic codes of society. Culture, seen as a product of social interaction and the greatest heritage of society, is national and the result of the life of the nation to which it belongs. Religion, language, historical heritage, economy, politics, wars, art, literature, law, environment, trade and moral are the main elements that make up the culture. The culture that takes place in this context concerns all members of the society and turns the society into a whole. One of the most basic duties of the individual in a society is to recognize and learn the culture they live in, and to ensure the continuity of this culture. This can only be achieved through education. The most important method of this situation is to design the mother tongue lessons together with language teaching as a culture transfer lesson. The concept of cultural value comes across a very wide range. In order to transfer this wide spectrum to future generations, environments should be created in order to transfer all kinds of material and spiritual values that constitute the Turkish culture to the students. The programs of the courses should be prepared accordingly. The most important lesson that can serve these purposes within the courses is Turkish course. In this study, the opinions and practices of teachers about the teaching of cultural values in secondary school Turkish courses are discussed. The practices of the teachers in the transfer of culture in their classrooms, the ways and methods they use in these practices and the sources they use to gain cultural values constitute the content of the research. The aim of the research is to reveal the extent to which Turkish teachers implement the culture transfer and the extent to which these practices are carried out. Again according to the opinions of the teachers, the status of the textbooks in terms of transferring our cultural values is among the questions that the research is looking for.

\section{Method}

This research is designed according to the case study of qualitative research methods. The idea of collecting in-depth data in the research is the main factor in preferring qualitative research. The case study process consists of the development of research questions, determination of the situation to be studied, determination of the unit of analysis, creation of the study group, collection of data and analysis and interpretation of the collected data. This process was followed in the research. Since qualitative methods are used in this research, purposive sampling has been applied. The study group consisted of thirteen Turkish teachers working in central districts of Kayseri in the 2017-2018 academic year. Six of the teachers were male and seven were female. Three of the teachers are graduate and ten are undergraduate. Teachers in the sample have experience in different professional years. In order to collect data, the interview technique was applied and a semi-structured interview form was prepared for this purpose. In the analysis of the data, content analysis was used from qualitative research methods. After the data obtained from the research were transferred to the computer, the statements of the interviewers were coded. Thus, themes and sub-themes have been reached. Research questions were taken into consideration in the creation of themes and sub-themes.

\section{Result and Discussion}

According to the results of the research, Turkish language teachers express the purpose of the transfer of cultural heritage as the acquisition of national and moral values, ensuring social cohesion, gaining cultural awareness and continuity and finding our own place in universal culture. In Turkish lessons, teachers carry out various activities for transferring our cultural heritage to future generations. Making drama, introducing historical figures, preferring cultural topics in writing process, analyzing folk songs, idioms and proverb works, making cultural class exhibitions, performing old and patient visits with class and book presentation are the main ones of these activities. People who are unaware of their culture and who do not know their history will benefit neither themselves nor their country. For this reason, all activities aimed at cultural transfer in Turkish lessons are considered important for the new generations to gain their culture and to serve their country. According to the research, it is seen that the teachers find the secondary school Turkish textbooks insufficient in terms of text selection and visual content. Teachers also state that cultural texts are irregularly distributed according to class level. Although many sources were used in the transfer of cultural heritage, interviewers stated that they used more books and internet in this sense. Today, in the age of informatics, the use of internet in transferring our cultural heritage is very important. Therefore, it is considered as a necessity to create virtual environments where students can learn our intangible cultural heritage. Learning of living is very important in bringing our cultural heritage to students. Teachers should apply different methods and techniques in the process and create multiple learning environments for the students. In addition, media contents should be utilized in transferring culture to future generations. 
Giriş

Kültür, sosyal bilimler alanında, farklı boyutlarıyla ele alınan ve üzerinde en çok durulan farklı kavramlardan biridir. "Tarihsel, toplumsal gelişme süreci içinde yaratılan bütün maddi ve manevi değerler ile bunları yaratmada, sonraki nesillere iletmede kullanılan, insanın doğal ve toplumsal çevresine egemenliğinin ölçüsünü gösteren araçların bütünü, hars, ekin” (TDK, 2005, s. 1282) olarak tanımlanan kültür; bir milleti var eden ve onu diğer milletlerden ayıran en temel özelliktir. "Kültür; toplum, insanoğlu, eğitim süreci ve kültürel muhteva gibi değişkenlerin ve bunlar arasındaki karmaşık ilişkilerin bir işlevidir” (Güvenç, 1994, s. 101). Kültür, bir milletin yaşam tarzı, dünyayı algılama ve anlamlandırma biçimi, maddi ve manevi değerlerinin bütünüdür. Kültür toplumun genetik kodlarını içine alan geniş bir yelpazedir. Sosyal etkileşimin bir ürünü ve toplumun en büyük mirası olarak görülen kültür millîdir ve ait olduğu milletin yaşayışının bir sonucudur. Sosyal anlamların paylaşımına olanak veren kültür bir yaşam tasarımıdır (Barker, 2008). Hayatın olağan akışı içerisinde meydana gelen kültür içerisinde birçok ögeyi barındırır. Ünalan'a (2002) göre din, dil, tarihi miras, ekonomi, politika, savaşlar, sanat, edebiyat, hukuk, çevre, ticaret ve ahlak kültürü meydana getiren başlıca unsurlardır. Bu bağlamda meydana gelen kültür toplumun bütün fertlerini ilgilendirmekte ve toplumu bir bütün haline getirmektedir. Bu nedenle toplumlar bir yandan kültürlerini her türlü tehlikelere karşı korurken bir yandan da onu gelecek kuşaklara aktarmak ister.

Bir milletin kültürünü gelecek kuşaklara aktarmasında en temel araç dildir. Dil kültürün temelini oluşturur. "Dil, onu konuşan ulusun yaşayış biçiminin, en geniş anlamda kültürünün, dünya görüşünün, tarih boyunca geçirdiği çeşitli evrelerin ve başka toplumlarla kurduğu ilişkilerin yansıtıcısıdır" (Aksan, 2001, s. 14). Dil, toplumun birleştirici gücüdür. Korkmaz'a (1980) göre bir insan iç ve dış dünya arasındaki bağlantıyı nasıl dil ile kuruyorsa bir toplumun fertleri arasındaki duygu ve düşünce paylaşımı da dil ile kurulmaktadır. Nesilden nesile aktarılarak bugünlere ulaşan ve bireyleri milletine, yurduna ve tarihine sıkı sıkıya bağlama işlevi bulunan dil, kişiyi geçmiş ile gelecek arasında kurulan zincirin bir parçası haline getirir" (Okuyan, 2012). Böylece bütün yönleri ile kendini ortaya koymaya çalışan ferde dil aracılığı ile tarih ve kültür okyanusunun kapıları aralanır. Bu yönüyle dil, bir toplum için adeta maziden gelip istikbale uzanan bir köprü işlevi görür.

İnsanlar, toplumsal işleyişin bir parçası olarak dili içinde yaşadığı sosyal çevreden öğrenir. "Dil toplumdan bağımsız olamaz. Birey doğumu ile kendisini bir dil sisteminin içinde bulur. Ana, baba, çevre, okul çocuğa dil vasıtası ile cemiyetin asırlar boyunca biriktirdiği hayat tecrübesini ve kültürünü de aktarır" (Kaplan, 2001, s. 12). Bu anlamda bireyler içerisinde bulunduğu toplumun kültür penceresinden yaşama anlam yükler. Melanlığlu'na (2008) göre aynı dili konuşan toplumlar yaşamı ve çevresinde gelişen olayları kendi dilinin penceresinden görmektedir. Porzig'e (1985) göre ise dil insanlara dünyayı anlamak ve ondaki görüntüleri yorumlamak için bir yol açar. İnsanlar dilin kendilerine sunduğu kavramlar ile düşünür ve dünyayı anlamlandırır. Fert içinde yaşadığı tolumun hafızasını dil ile anlar, duygu ve düşünce ve hayallerini dil ile anlatır ve dil ile toplumun bir parçası haline gelir. Böylece bireyler dilin kültürel bağlamı içinde yaşamını devam ettirir.

Bir toplumda ferdin en temel görevlerinden biri içinde yaşadığı kültürü tanımak, öğrenmek ve bu kültürün devamlılı̆ını sağlamaktır. Bunu da ancak bulunduğu toplumun kültürel birikimini görerek, duyarak ve onu yaşayarak yapabilir. "Kültürel yapının unsurları sosyal ortam içerisinde başka insanlarla iletişim kurarak değer hâline getirilir. Toplumsal yaşam içerisinde her kuşak kendinden önce yaşamış kuşağın deneyimlerinin yol göstericiliğinde yaşamı anlamlandırmaya çalışır" (Kalfa, 2013, s. 172). Kültürün bir parçası olan bu deneyim ve bilgiler ile değer yargılarını oluşturur. "Milletler de millî birlik ve beraberliklerini korumak için kültür ögelerini yeni kuşaklara aktarmak ve kazandırmak isterler. Milletin devamı için bireyler, kültürlerini yeterince tanımalı ve millî bilince sahip olmalıdır" (Güfta ve Kan, 2011, s. 240). Bu ancak eğitim yoluyla gerçekleştirilebilecek bir durumdur ve yöntemi de ana dili derslerinin dil dersi yanında bir kültür dersi olarak görülmesinden geçmektedir.

Dil öğretiminde temel amaç insanlara doğru iletişim becerisi kazandırarak bireylerin ait oldukları toplumların kültürel birikimini dil aracılığıyla gelecek kuşaklara ve farklı toplumlara aktarmalarını sağlamaktır (Demir ve Açık, 2011). Dil, milli kültürün en temel aktarıcısı durumundadır. Bu nedenle dil öğretimi aynı zamanda bir kültür öğretimidir. Anadili öğretiminin temeli olan Türkçe dersleri kültür aktarımı ve kültürel değerlerin öğretiminde önemli bir konuma sahiptir (Melanlıoğlu, 2008). İlköğretimde dilimizin bütün inceliklerinin ve güzelliklerinin öğretilmesinin ve bilinçli kullanma becerisinin kazandırılmasının amaçlandığı Türkçe derslerinin, somut olmayan kültürel mirasımızın tanınmasında, öneminin kavranmasında, bilinç ve duyarlııı oluşturulmasında, korunmasında ve geleceğe aktarılmasında rolü büyüktür (Okuyan, 2012, s. 36). Küreselleşen dünya düzeninin kültürler üzerindeki yıkıcı etkilerine karşı geleceğimizin mimarı olan çocuklarımızı kültürel değerlerimizle donatmak, onları kültürümüze sahip çıkan, koruyan duyarlı bir vatandaş olarak yetiştirmek millî bekamız açısından hayatî bir önem taşımaktadır. "Sorun, günümüzde artık önemini yitirmeye başlayan ve anlam ifade etmez hâle gelen, basit olarak algılanan kültür değerleri sorunu değil var oluş sorunudur, millî varlığımızı devam ettirme sorunudur" (Kolaç, 2009, s. 22). Bu sorunun üstesinden gelebilmenin yolu ise kültürümüzün gelecek kuşaklar tarafından benimsenip yaşam biçimi haline getirilmesinden geçmektedir.

Kültür ve kültürel değer kavramı çok geniş bir yelpazede karşımıza çıkmaktadır. Bu geniş yelpazenin gelecek kuşaklara aktarılabilmesi için okullarda Türk kültürünü oluşturan her türlü maddi ve manevi değerleri öğrencilere aktaracak ortamlar oluşturulmalı, derslerin programları da buna uygun olarak hazırlanmalıdır. Dersler içinde bu amaçlara hizmet edebilecek; bahsedilen değerlerin öğrencilere aktarılmasını, benimsetilmesini ve sevdirilmesini sağlayacak en önemli ders Türkçe dersidir. Türkçe derslerinde bu doğrultuda gerekli planlama ve uygulamalara yer verilmeli, bu anlamda gereken hassasiyet ilgililerce gösterilmelidir. Çünkü Türkçe dersinin içeriği, Türk kültürünü aktarmayı mecburi kılmaktadır (Uyar, 2007, s. 29). Ders kitaplarında yer alan metinlerin seçimi de bu bağlamda önem arz etmektedir. Ders kitaplarında yer alacak metinlerin seçimi rastgele yapılmamalıdır. Öncelikle, edebî eserler amaca uygun olarak titiz bir taramadan geçirilmeli; mümkün olduğunca edebî zevke,

| Kastamonu Eğitim Dergisi, 2020, Vol. 28, No. 3 | 
aktarılacak değerlere ve programda belirtilen amaçlara uygun özelliklere sahip metinler seçilmelidir (Bulut ve Orhan, 2012, s. 308). Seçilen bu metinler ise bir kültür aktarım aracı olarak öğretmenlerce en iyi şekilde kullanılabilmelidir. Kitaplarda yer alan bu metinler aracılığıyla öğrencilere edebiyat ve kültür dünyasının kapıları aralanmalı ve onların geçmiş ile gelecek kuşaklar arasında bir köprü görevinde bulundukları fark ettirilmelidir.

Kültür aktarımı açısından Türkçe derslerini yürüten öğretmenlere çok önemli görevler düşmektedir. Saygı, sevgi, hoşgörü, misafirperverlik, dini değerler, vatanseverlik gibi somut olmayan kültürel değerler yönünden, öğretmenler öğrencilerine örnek olurken derslerinde yaptıkları etkinliklerle, verdikleri araştırma görevleriyle, önerdikleri okuma kitapları ile öğrencilere kazandırımak istenen değerleri aktarabilmelidirler. Yaptıkları sanatsal kültürel faaliyetlerle hem öğrencilerini kültürel hayatın bir parçası haline getirebilmeli hem de Türk toplumu tarafından benimsenerek kültür abidesi haline gelmiş Yunus Emre, Mevlana, Nasrettin Hoca gibi değerleri öğrencilerine tanıtmalıdırlar. Türkçe dersleri, küresel olguların milli kültürümüzü yıkıcı etkilerine karşı geleceğimiz olan çocuklarımızı bilinçlendirme ve onlara kültürel duyarlılık kazandırabilmek için bir fırsat olarak görülmelidir. Öğretmenler bu minvalde gerçekleştirecekleri her uygulamada taşıdıkları sorumluluğun farkında ve bilincinde olmalıdır. Bu anlamda farklı toplumların kültürel birikimlerinden de söz etmeli ve öğrencilerin zihinlerinde oluşabilecek kültür çatışmalarının önüne geçmelidirler (Deveci, 2009). Öğretmenler öğrenme ortamlarını kültür öğeleriyle zenginleştirip uyaranı kültürel mirasımız olan çoklu öğrenme ortamları olarak tasarlamalıdırlar (Göçer, 2013). Ancak böyle ortamlarda öğrencilerde kültürel farkındalık oluşturulur ve öğrenciler sahip oldukları kültürel miras hakkında düşünmeye sevk edilebilir.

Bu araştırmada ortaokul Türkçe derslerinde kültürel değerlerin öğretimine yönelik öğretmenlerin görüş ve uygulamaları ele alınmaktadır. Öğretmenlerin sınıflarında kültür aktarımına ilişkin gerçekleştirdikleri pratikler, bu pratiklerde kullandıkları yol ve yöntemler ile kültürel değerlerin kazandırılmasında başvurdukları kaynaklar araştırmanın muhtevasını oluşturmaktadır. Yine Türkçe derslerini yürüten öğretmenlerin kültürel mirasımızın aktarımında önemli buldukları noktalar ile gelecek kuşaklara daha iyi bir kültür aktarımı yapabilmek için sundukları öneriler, çalışmanın temel amacını oluşturmaktadır. Bu yolla artık sosyal medya ve iletişim çağının oluşturduğu sanal bir ortamda yetişen öğrencilerin sahip oldukları kültürel mirası daha iyi anlayıp özümsemelerine yönelik öğrenme ortamlarında gerçekleştirilen uygulamalara bir ayna tutmak amaçlanmaktadır. Araştırma ile Türkçe öğretmenlerinin kültür aktarımına yükledikleri anlam ile buna yönelik gerçekleştirdikleri sınıf içi uygulamaların hangi boyutlarda yapıldığını ortaya çıkarmak hedeflenmektedir. Yine öğretmenlerin görüşleri doğrultusunda ders kitaplarının kültürel değerlerimizi aktarım konusunda yeterlilik durumu araştırmanın cevap aradığı sorular içerisindedir.

\section{Problem Cümlesi}

Ortaokul Türkçe derslerinde kültürel değerlerin aktarımına yönelik öğretmen görüş ve uygulamaları nasıldır?

\section{Alt Problemler}

1. Ortaokul Türkçe derslerinde kültür aktarımının önemine yönelik öğretmen görüşleri nasıldır?

2. Ortaokul Türkçe derslerinde kültürel mirasın kazandırılmasına yönelik öğretmen uygulamaları nelerdir?

3. Öğretmen görüşlerine göre Türkçe ders kitapları kültürel mirasın aktarımı konusunda yeterli midir?

4. Ortaokul Türkçe derslerinde kültürel mirasın kazandırılabilmesi için yararlanılan kaynaklar nelerdir?

\section{YÖNTEM}

Araştırmanın yöntemini, kullanılan araştırma modeli, çalışma grubu, veri toplama araçları ile verilerin tanımlanmasında kullanılan yöntem ve teknikler oluşturmaktadır.

\section{Araştırmanın Modeli}

Bu araştırma, nitel araştırma yöntemlerinden durum çalışmasına (case study) göre desenlenmiştir. Yin'e (2012) göre durum çalışması nasıl ve neden soruları ile başlayan bu sorular bağlamında kavramsal bir çerçeve sunan araştırma metodudur. "Durum çalışması güncel bir olguyu kendi gerçek yaşam çerçevesi içinde çalışan ve araştırmacının kontrol edemediği bir olgu ya ya da olayı derinliğine incelemesine olanak veren bir araştırma yöntemidir” (Yıldırım \& Şimşek, 2016: 289). Durum çalışmaları hem bir araştırma hem de bir öğretim yöntemi daha genel ifade ile bir öğrenme metodudur (Flyvbjerg, 2016). Bu araştırmada ortaokul Türkçe derslerindeki kültür aktarımına yönelik uygulamalar bir durum ya da olgu olarak belirlenmiştir. Araştırmada derinlemesine veri toplanma düşüncesi, nitel durum araştırmasının tercih edilmesindeki temel etkendir. Durum çalışmaları açıklayıcı, keşif, tanımlayıcı olarak üç başlıkta incelenebilir (Yin, 2012). Bu araştırmada açıklayıcı durum çalışması modeli kullanılmaktadır. Açıklayıcı durum çalışmalarında bir durum hakkında derinlemesine bilgi vermek amacı vardır (Aytaçlı, 2012). Bir durumun açıklandığı bu model benzer modellerin yorumlanmasına olanak tanır.

Durum çalışmalarında araştırma süreci; araştırma sorularının geliştirilmesi, çalışılacak durumun belirlenmesi, analiz biriminin tespiti, çalışma grubunun oluşturulması, verilerin toplanması ile toplanan verilerin analiz edilmesi ve yorumlanması sürecinden oluşmaktadır (Yıldırım ve Şimşek, 2016, s. 292). Araştırmada bu süreç takip edilmiştir. Durum çalışmalalarında bir genellemeden ziyade durumun en iyi şekilde anlaşılması amaçlanır (Denzin \& Lincoln, 1994). Bu araştırmada durum çalışmalarının ruhuna uygun bir şekilde, bir duruma ilişkin veri toplama, bu verileri analiz etme ve yorumlama aşamalarını içeren sistematik bir yol izlenmiştir. Böylelikle araştırma sürecinde elde edilen verilerin açık ve anlaşılır bir biçimde raporlaştırılması amaçlanmıştır. Ayrıca takip edilen bu sistematik süreç içerisinde, derinlemesine bilgilere ulaşılması ve elde edilen birçok ham verinin belli kategoriler çerçevesinde ortaya konulması ve alan yazın bulguları bağlamında bu verilerin yorumlanması gerçekleştirilmiştir. 


\section{Çalışma Grubu}

Bu araştırmada nitel yöntemler kullanıldığından amaçlı örnekleme yoluna başvurulmuş ve on üç kişiden oluşan bir çalışma grubu oluşturulmuştur. "Amaçlı örnekleme tam anlamıyla nitel araştırma geleneği içinde ortaya çıkmış ve zengin bilgiye sahip olduğu düşünülen durumların derinlemesine çalışılmasına olanak veren bir örnekleme yöntemidir" (Yıldırım ve Şimşek, 2016, s. 118). Belirlenen çalışma grubu 2017-2018 eğitim öğretim yılında Kayseri merkez ilçelerinde görev yapan ve farklı hizmet deneyimi olan on üç Türkçe öğretmeninden oluşmaktadır. Öğretmenlerin altısı erkek yedisi kadındır. Üçü yüksek lisans onu lisans mezunudur. Örneklemde yer alan öğretmenler farklı mesleki yıllarda deneyime sahiptir.

\section{Verilerin Toplanması}

Araştırmada veri toplamak amacıyla görüşme tekniğine başvurulmuştur. "Nitel araştırmalarda kullanılan görüşme tekniği, üzerinde araştırma yapılan kişilerin bakış açılarını, anlam dünyalarını ortaya koyma, dünyayı onların gözleriyle görme amacına hizmet edecek şekilde kullanılmaktadır" (Cemaloğlu, 2011, s. 152). Hazırlanan yarı yapılandırılmış görüşme formu ile önce 4 öğretmenle görüşülerek pilot uygulama yapılmıştır. Pilot uygulama verilerine ve uzman görüşlerine göre görüşme formu üzerinde gerekli değişiklikler yapılmıştır. Ön görüşme bağlamında ortaya çıkan kavramlardan hareketle sorular yeniden düzenlenmiştir. Öncesinde 3 olan soru sayısı 6’ya çıkarılmıştır. Bu durum araştırmada kullanılan soruların geçerliğini desteklemesi bakımından önemlidir. Araştırma kapsamında ele alınacak noktaları belirlemeye yönelik olarak soru sayısı arttırılmış böylece araştırmanın alt problemlerinin cevabını bulmaya dönük sorular oluşturulmuştur. Ancak görüşme sonunda konu ile ilgili farklı görüşlere de yer verilmiş görüşmelerin mümkün olduğunca fazla veri elde edecek şekilde uzun geçmesine çalışılmıştır. Görüşmelere yeterince zaman ayrılmış, öğretmenler sorulara içtenlikle cevap vermişlerdir. Görüşme esnasında not alınmış daha sonra görüşme kayıtları bilgisayar ortamına aktarılarak analiz edilmiştir.

\section{Verilerin Tanımlanması}

Araştırmacı tarafından tüm veriler bilgisayar üzerinde yazılı hale getirilmiştir. Elde edilen verilerin analizinde, nitel araştırma yöntemlerinden içerik analiz kullanılmıştır. "İçerik analizinde temel amaç toplanan verileri açıklayabilecek kavramlara ve ilişkilere ulaşmaktır" (Yıldırım ve Şimşek, 2016, s. 242). Araştırma neticesinde elde edilen veriler bilgisayar ortamına aktarıldıktan sonra, görüşmecilerin ifadeleri kodlanarak araştırmanın temaları ve alt temalarına ulaşılmıştır. Tema ve alt temaların oluşturulmasında araştırmanın problemleri göz önünde bulundurulmuştur. Patton'a (2014) göre nitel araştırmacı elde ettiği ham verileri içerik analizine tabi tutar böylece bu verileri kategori ve alt kategorilere ayırıp okuyarak süreç içerisinde ulaştığı tema, örüntü, anlayış ve iç görüleri araştırmanın betimlemelerine dönüştürür. Çalışmada bu süreç takip edilmiş ve araştırmanın genel örüntüsü ortaya konulmaya çalışılmıştır.

\section{BULGULAR}

Bu bölümde araştırma sürecinde elde edilen bulgular yapılan içerik analizine göre tablolar halinde sunulmaktadır. Araştırma neticesinde 5 ana temaya ulaşılmış ve bu temalar çerçevesinde araştırmanın örüntüsü ortaya konulmaya çalışılmıştır. Bu bağlamda 1. Tema kültürel mirasın aktarımının amacını belirlemeye yönelik olan temadır.

Tablo 1. Kültürel mirasın aktarımında amaç

\begin{tabular}{lcc}
\hline Kod Listesi & Frekans (f) & Yüzde (\%) \\
\hline Amaç & 13 & 100 \\
\hline Milli manevi değerleri kazandırmak & 11 & 84,61 \\
Toplumsal uyumu kolaylaştırmak & 7 & 53,84 \\
Kültürel farkındalık kazandırmak & 5 & 38,46 \\
Kültürel sürekliliği sağlamak & 4 & 30,76 \\
Evrensel kültür içerisinde kendi yerimizi almak & 2 & 15,38 \\
\hline
\end{tabular}

Tablo 1'e göre, görüşme yapılan öğretmenlerin kültürel mirasımızın aktarımının amacını, milli ve manevi değerlerin kazandırıması (11 kişi), toplumsal uyumun sağlanması (7 kişi), kültürel farkındalık (5 kişi) ve sürekliliğin (4 kişi) kazandırılması ile evrensel kültür içerisinde kendi yerimizi almamız (2 kişi) olarak gördükleri ifade edilebilir. Temaya ilişkin verilen cevapların bir bölümü aşağıya alınmıştır.

Türkçe derslerinde kültür aktarımını tabi ki önemli buluyorum. Çünkü Türkçe dersi hem müfredat hem içerik olarak bir kültür dersidir. Bu derslerde öğrenciler kültürümüz ile tanışmakta ve milli manevi değerlerimizi kültürel özelliklerimizi öğrenmektedirler (1. Görüşmeci).

Okul öğrencinin topluma uyum sağlamasında etkili olan en önemli yerdir. Kültür ise toplumu ayakta tutan toplumun varlığını sağlayan bir öğedir. Çocuk Türkçe derslerinde dil öğrenmenin yanında kültürünü de öğrenerek topluma uyum sağlar (7. Görüşmeci).

Kültür aktarımı sadece Türkçe dersleriyle sınırlı kalmamalı ama kültür aktarımının en rahat Türkçe dersinde yapılacağını inkâr edemeyiz. Anadili öğretiminden kültürü ayrı düşünemeyiz kültürel değerlerimizle öğrenciler dünyaya kendimize ait çerçeveden bakmayı öğrenirler (13. Görüşmeci).

Araştırmada ulaşılan 2. Tema, kültürel mirasımızın aktarımına ilişkin sınıf içi ve sınıf dışarısında gerçekleştirilen uygulamalardır. Öğretmenlerin eğitim sürecinde hangi faaliyetlerle bunu yaptıklarına yönelik bulgular Tablo 2'de sunulmuştur.

|Kastamonu Eğitim Dergisi, 2020, Vol. 28, No. 3| 
Tablo 2. Kültür aktarımına yönelik uygulamalar

\begin{tabular}{lcc}
\hline Kod Listesi & Frekans (f) & Yüzde (\%) \\
\hline Uygulamalar & 13 & 100 \\
\hline Drama & 10 & 76,9 \\
Tarihi şahsiyetleri tanıtma & 8 & 61,53 \\
Kültürel konularda metin ve şiir yazdırma & 7 & 53,84 \\
Türküler ve türkülerin hikâyelerini inceleme & 5 & 38,46 \\
Belgesel, film vb. video izletme & 5 & 38,46 \\
Deyim ve atasözlerine yönelik çalışmalar & 5 & 38,46 \\
Kitap tanıtımı & 4 & 30,76 \\
El sanatlarına yönelik sınıf çalışması & 3 & 23,07 \\
Kültürel sınıf sergisi yapma & 2 & 15,38 \\
Yaşlı ve hasta ziyaretleri & 2 & 15,38 \\
\hline
\end{tabular}

Tablo 2’ye göre, öğretmenlerin kültür aktarımına ilişkin sınıf içi uygulamaları, drama yaptırma (10 kişi), tarihi şahsiyetleri tanıtma (8 kişi), yazma sürecinde kültürel konuları tercih etme (7 kişi), türküler ve türkülerin hikâyelerini inceleme (5 kişi), kültürel değerlerimizi konu edinen belgesel, film vb. izletme (5 kişi), deyim ve atasözü çalışmaları (5 kişi), kitap tanıtımı (4 kişi), el sanatlarına yönelik sınıf çalışmaları (3 kişi), sınıfla beraber yaşlı ve hasta ziyareti gerçekleştirme (2 kişi) ve kültürel sınıf sergisi yapmadır. (2 kişi). Görüşme sürecinde temaya ilişkin elde edilen ifadelerin bir bölümüne aşağıda yer verilmektedir.

Kültürel mirasımız olan şahsiyetleri mutlaka drama yoluyla tanıtmaya çalışırım. Bu Karagöz Hacivat olabilir, Nasreddin Hoca olabilir, Keloğlan olabilir... Zaten çocuklar çok seviyorlar bunları canlandırmayı. Hem eğleniyor hem de bu değerleri tanımış oluyorlar (6. Görüşmeci).

Elbette kültürel değerlerimizi öğrencilerime tanıtıp bu değerlerimizi gelecek kuşaklara aktarmaya yönelik derslerimde uygulamalar yapıyorum. Mesela meddah hikâyelerine yönelik videolar izletiyorum (1. Görüşmeci).

Evet derslerimde kültürel mirasımızın aktarımına yönelik faaliyetler gerçekleştirmeye çalışıyorum. Özellikle kendi sınıfımla yaşlı ziyaretleri ve hasta ziyaretleri yaptık. Bunların kültürümüzün bir parçası olduğunu öğrencilerime kazandırmaya çalışıyorum (5. Görüşmeci).

Kültürel değerlerimizin (kına gecesi, dügünlerimiz vb. ) canlandırılmasına yönelik tiyatro ve drama görevleri veriyorum (10. Görüşmeci).

7. Sınıflarda bu yıl "Zamana Vurulan Kirkit" diye bir şiir vardı. Bu şiiri işlerken sınıfa kilim getirdik ve öğrencilerimizle kilimi inceledik. Öğrencilerime kilimin dokunuşu hakkında canlandırmalar yaptırdım. Ayrıca öğrencilerime kültürel mirasımız olarak evlerinde neler olduğu konusunda araştırma yaptırdım ve sınıfa örnekler getirdiler danteller, işlemeler, örgüler ve birçok kültürümüze has ürünler getirdiler bunlarla sınıf sergisi yaptık. Daha sonra okul müdürümüz bunu çok beğendi ve bunu okul sergisi olarak 3 gün sergiledik (2. Görüşmeci).

Araştırma sürecinde ulaşılan 3. Tema kültürel mirasımızın aktarımında ders kitaplarının niteliğidir. Öğretmenlerin bu anlamda ders kitaplarına yönelik görüşleri Tablo 3'te sunulmaktadır.

Tablo 3. Kültür aktarımında ders kitaplarının niteliği

\begin{tabular}{lcc}
\hline Kod Listesi & Frekans (f) & Yüzde (\%) \\
\hline Ders Kitaplarının Niteliği & 13 & 100 \\
\hline Metin seçimi açısından yetersizdir. & 11 & 84,61 \\
Görsel içerik açısından yetersizdir. & 9 & 69,23 \\
Metinler sınıf düzeylerine göre düzensiz dağılım göstermektedir. & 6 & 46,15 \\
\hline
\end{tabular}

Tablo 3'e göre, kültürümüzün gelecek kuşaklara aktarımı açısından öğretmenlerin ders kitaplarını metin seçimi (11 kişi), görsel içerik (9 kişi) ve kültürel mirasımıza yönelik metinlerin sınıf düzeylerine göre düzensiz dağılımı (6 kişi) yönlerinden yetersiz bulduğu ifade edilebilir. Bu temaya yönelik elde edilen verilerin bir bölümü aşağıda sunulmuştur.

Ders kitaplarını kültür aktarımı açısından yeterli bulmuyorum. Kültürel değerlerimize ait metinlerin belli bir plan doğrultusunda müfredatta mutlaka yer alması gerektiğini düşünüyorum. Aşamalı olarak 5,6,7,8. Sınıfların her sınıf düzeyinde kültürel mirasımız ve bunlara ait metinler yer almalı ve öğrencilerimiz temel eğitimi bitirdiğinde kültürel yönden belli bir donanıma ulaşmıs olarak mezun olmalıdır (4. Görüşmeci).

Öncelikle bu kitaplar kültürel değerlerimize yönelik metinler yönünden yetersiz (9. Görüşmeci).

Bu yıl 7. Sınıflarda Bir Fincan Kahve isimli bir metin vardı ve metinle kahve kültürümüzü öğrencilerimize tanıttık ve hem metin hem ders çok sevildi. Benzer metinler mutlaka tüm sınıf düzeylerinde olmalı (12. Görüşmeci).

Kitapların görselleri bu konuda yetersiz sizin saatlerce konuşarak anlattığınız bir kültürel değeri bir resim çok daha etkili anlatabilir. Mesela Nasrettin Hoca'nın eşeğe ters bindiği bir resim çocukların çok fazla dikkatini çekip Nasrettin Hocayı gerçek manada benimsemeleri ve anlamaları konusunda çok etkili olabilmektedir (4. Görüşmeci).

Araştırma bağlamında ulaşılan 4. Tema kültürel mirasımızın aktarımında öğretmenlerin kullandığı kaynaklardır. Bu temada ulaşılan sonuçlar Tablo 4'te gösterilmektedir. 
Tablo 4. Kültür aktarımında kullanılan kaynaklar

\begin{tabular}{lcc}
\hline Kod Listesi & Frekans (f) & Yüzde (\%) \\
\hline Kaynaklar & 13 & 100 \\
\hline Kitaplar & 12 & 92,3 \\
Internet & 11 & 84,6 \\
Birincil kaynaklar & 4 & 30,7 \\
Geleneksel oyunlar & 3 & 23,0 \\
Yöresel numuneler & 1 & 7,69 \\
\hline
\end{tabular}

Araştırmanın yöntemini, kullanılan araştırma modeli, çalışma grubu, veri toplama araçları ile verilerin tanımlanmasında kullanılan yöntem ve teknikler oluşturmaktadır.

Tablo 4'e göre, öğretmenlerin somut olmayan kültürel mirasın aktarımında kullandıkları kaynaklar, kitaplar (12 kişi), internet (11 kişi), birincil kaynaklar (4 kişi), geleneksel oyunlar (3 kişi) ve yöresel numunelerdir (1 kişi). Öğretmenlerin kültür aktarımında kullandıkları kaynaklara ilişkin bazı öğretmen görüşleri aşağıda verilmiştir.

Bu konuda en çok ders kitaplarından yaralanıyorum. Bunun için kültür aktarımına yönelik ders kitaplarına alınan metinleri çok önemsiyorum (6. Görüşmeci).

Merkeze bağlı bir köyde görev yaptığım için bu konuda birincil kaynaklar (köyün yaşlıları) ve yöresel model ve numunelerden yararlanma olanağım var ve bundan oldukça fazla yararlanmaya çalışıyorum (3. Görüşmeci).

Ders kitapları öncelikli olmak üzere internetten de bu konuda yararlanıyorum (4.Görüşmeci).

Geleneksel oyunlarımızı öğrencilerime kazandırmaya çalışıyorum. Çocukken oynadığımız beştaş, dokuztaş, çelik çomak gibi oyunların kurallarını öğretiyor zaman zaman da öğrencilerime bu oyunları oynatmaya çalışıyorum (11. Görüşmeci).

Araştırmanın 5. Teması öğretmenlerin öğrencilere mutlaka kazandırılması gerektiğini düşündüğü ve ders kitaplarında yer verilmesini istediği kültürel miras unsurlarıdır. Bu bağlamda ulaşılan sonuçlar Tablo 5'te sunulmaktadır.

Tablo 5. Önerilen kültürel miras unsurları

\begin{tabular}{lcc}
\hline Kod Listesi & Frekans (f) & Yüzde (\%) \\
\hline Önerilen Kültürel Miras Unsurları & 13 & 100 \\
\hline Vatan, millet, bayrak, dil sevgisi & 12 & 92,30 \\
Türk büyüklerimiz & 11 & 84,61 \\
Dini değerlerimiz & 10 & 76,92 \\
Bayram geleneklerimiz & 10 & 76,92 \\
Hoşgörü, yardımseverlik, dürüstlük vb. değerlerimiz & 9 & 69,23 \\
Mani, ninni, türkü, destan, efsanelerimiz & 8 & 61,53 \\
Geleneksel oyunlarımız & 7 & 53,84 \\
Düğün, nişan, kına gecesi vb. adetlerimiz & 6 & 46,15 \\
Türk misafirperverliği & 6 & 46,15 \\
Sofra kültürümüz & 4 & 30,76 \\
Görgü kurallarımız & 3 & 23,07 \\
Geleneksel el sanatlarımız & 3 & 23,07 \\
\hline
\end{tabular}

Tablo 5'e göre, öğretmenlerin 4 yıllık ortaokul döneminde öğrencilere kazandırılmasının gerektiğini düşündükleri ve ders kitaplarında yer verilmesini istedikleri başlıca kültürel miras unsurları vatan, millet, bayrak, dil sevgisi (12 kişi), Türk Büyüklerimiz (11 kişi), dini değerlerimiz (10 kişi), bayram geleneklerimiz (10 kişi), hoşgörü, yardımseverlik, dürüstlük vb. değerlerimiz (9 kişi), mani, ninni, türkü, destan ve efsane gibi edebi türlerimiz (8 kişi), geleneksel oyunlarımız (7 kişi), düğün, nişan, kına gecesi vb. adetlerimiz (6 kişi), Türk misafirperverliği (6 kişi), sofra kültürümüz (4 kişi), görgü kurallarımız (3 kişi) ve geleneksel el sanatlarımızdır (3 kişi). Bu temaya yönelik bazı görüşler aşağıda yer almaktadır.

Bayram geleneklerimiz, düğünlerimiz; mani, ninni, ağıt ve türkülerimiz; kilim, örgü, dantelimiz; Yunus Emre, Mevlana, Nasrettin Hocamız; hepsinden önemli olan, bayrak, vatan, millet ve dil sevgimiz, dini değerlerimiz öğrencilerimize mutlaka kazandırılmalıdır (2. Görüşmeci).

Öncelikle toplumsal ve insani değerlerimiz doğruluk, dürüstlük, hoşgörü vb. sonra geleneklerimiz, bayramlarımız, atasözlerimiz, deyimlerimiz, türkülerimiz kısaca bize ait olan bütün değerlerin öğrencilere kazandırılması gerektiğini düşünüyorum (9.Görüşmeci).

Ahlaki değerlerimiz (doğruluk, dürüstlük, hoşgörü vb.) sanat değerlerimiz, müziğimiz, misafir ağırlama, bayram, dügün, yardımlaşma geleneklerimiz kısaca bize ait olan bütün değerlerimiz öğrencilerimize kazandırılmalıdır (6. Görüşmeci).

\section{TARTIŞMA}

Kültür bir milletin bütün fertlerini yakından ilgilendiren bir kavramdır. Bir toplumun asırlar süren tecrübelerine dayanan ve onu diğer toplumlardan ayıran en önemli nitelik olarak görülen kültür ancak toplumun bütününde yaşama olanağı bulursa varlığını sürdürebilir. Türkmen (2012)'e göre bir milletin sahip olduğu kültürel birikim o milletin sadece belli bir kesiminin onu yaşatması ile devamlılı̆ını sağlayamaz. Sahip olunan bu birikimin uzun yıllar devam ettirilebilmesi için çocuğundan gencine, gencinden yaşlısına bütün bir toplum tarafından bilinip, korunup, yaşatılmasına ihtiyaç vardır. Bunun yolu ise eğitimden geçmektedir. Eğitim 
ortamlarında kültür aktarımına ilişkin yapılacak her faaliyet öğrencilerin sahip oldukları kültürel birikimi tanıma, anlama ve yaşatmaları adına bir yapı taşı vazifesi görecektir. Dil ve kültür arasındaki derin münasebet (Kaplan, 2003) dikkate alındığında ana dili dersi olan Türkçe dersleri kültür aktarımının mihenk taşı olarak karşımıza çıkmaktadır. Bu çalışmada ortaokul Türkçe öğretmenlerinin kültürel mirasımızın aktarımına ilişkin görüşleri ve sınıf içi uygulamaları ile kültür aktarımı sürecinde yararlandıkları kaynaklar tespit edilmiş ve değerlendirilmiştir.

Araştırma sonuçlarına göre Türkçe öğretmenleri, kültürel mirasın aktarımının amacını, öğrencilere millî ve manevî değerlerin edindirilmesi, toplumsal uyumun sağlanması, kültürel farkındalık ve sürekliliğin kazandırılması ile evrensel kültür içerisinde kendi yerimizin bulunması olarak ifade etmektedirler. Oğuz (2013, s. 11)' a göre kültürel miras kavramı "değerli bir halının, nitelikli karagöz tasvirlerinin veya oyalı bir yazmanın korunmasını değil, onları üreten, yaşatan ve kuşaktan kuşağa aktaran bilgi, gelenek ve birikimin bütün unsurlarıyla korunmasını hedeflemektedir." Göçer (2012)' e göre kültür bir toplumun gelenek ve göreneklerinin, yaşam tarzlarının kısacası tarihinin dil aracılığıyla günümüze ulaşmış belgesidir. Bunu sürdürebilmenin en sağlam yolu ise dil köprüsü ile bunu gelecek kuşaklara aktarmaktan geçmektedir. Bu anlamda görüşme yapılan öğretmenlerin kavramsal olarak kültürel miras terimine ilişkin ortaya koydukları bakış açısının kültürel birikimimizin devamı ve yeni nesilde kültürel değerlerin kazandırılmasına yönelik olduğu ifade edilebilir. Öğretmenler toplumun sahip olduğu kültürel değer yargılarının öğrencilere aktarımı ile somut olmayan kültürel mirasın sürekliliğinin sağlanacağını ifade etmektedirler.

Türkçe derslerinde öğretmenler, kültürel mirasımızın gelecek kuşaklara aktarılmasına yönelik çeşitli sınıf içi ve sınıf dışı faaliyetler gerçekleştirmektedirler. Drama yaptırma, tarihi şahsiyetleri tanıtma, yazma sürecinde kültürel konuları tercih etme, türküler ve türkülerin hikâyelerini inceleme, kültürel değerlerimizi konu edinen belgesel, film vb. izletme, deyim ve atasözü çalışmaları, kültürel sınıf sergisi yapma, sınıfla beraber yaşlı ve hasta ziyareti gerçekleştirme, el sanatlarına yönelik sınıf çalışmaları ve kitap tanıtımı bu faaliyetlerin başlıcalarıdır. Ekici (2004)’ye göre küresel dünyamızda hızlı bir şekilde yok edilerek tüketilen ve yeni nesil tarafından benimsenmeyip korunmayan bir miras, eski binalar gibi kendiliğinden yıkılıp yok olmaya mahkûmdur. Bu bağlamda ortaokul düzeyinde somut olmayan kültürel mirasın aktarımına ilişkin öğretmenlerin yapacağı her bir etkinlik, her bir faaliyet öğrencinin zihninde derin izler bırakacak ve bu mirasın gelecek kuşaklara aktarılmasında çok önemli bir işlev görecektir. Kaplan (2003)'a göre bir memleketin maddî ve manevî birikimini yaratanlar o memleketin kültürlü insanlarıdır. Kültüründen habersiz, tarihini bilmeyen ve diline yabancı insanların ne kendilerine ne de memleketlerine bir faydası olur. Bu nedenle Türkçe derslerinde gerçekleştirilen kültür aktarımına dönük bütün faaliyetler yeni kuşakların kültürlenmesi ve memleketlerine büyük bir şevk ve coşku ile hizmet etmeleri adına oldukça önemli görülmektedir.

Kültürel mirasımızın gelecek kuşaklara taşınmasında Türkçe ders kitaplarının önemli bir rolü vardır. Kitaplarda yer alacak Karagöz ile Hacivat, Nasrettin Hoca ve Keloğlan gibi değerler, geleneksel çocuk oyunları, el sanatları, sözlü gelenek ürünleri, toplumsal uygulama ve ritüeller, bayram gelenekleri, gösteri sanatları gibi kültürel mirasımızın konusunu teşkil eden metinler ile öğrenciler kültürel varlığımızı tanıyıp benimseyecektir. Yapılan araştırmaya göre kültürel varlığımızın gelecek kuşaklara aktarımı açısından öğretmenlerin ortaokul Türkçe ders kitaplarını metin seçimi, görsel içerik ve kültürel mirasımıza yönelik metinlerin sınıf düzeylerine göre düzensiz dağılımı açılarından yetersiz bulduğu görülmektedir. Kolaç’ın (2009) yaptığı araştırmada da ilköğretim birinci basamak Türkçe ders kitaplarının sadece \%11'inde kültürel değerlere yer verildiği tespit edilmiştir. Hızlı bir şekilde küreselleşen dünyamızda bu sonuçlar üzüntü vericidir. Ders kitaplarının hazırlanması aşamasında kültürel mirasımıza ilişkin metinler ve temalar aşamalı bir biçimde gruplandırılarak sınıf düzeylerine göre ders kitaplarında yerini almalıdır. Öğrencilerin hangi sınıf düzeyinde hangi kültürel mirasımızı kazanacağı ve temel eğitimi bitirdiğinde bu anlamda hangi donanımları edinmiş olacağı önceden planlanmalıdır. Aksi takdirde dağınık ve düzensiz bir şekilde ders kitaplarında yer alacak kültürel değerler, öğrencilerde kafa karışıklığına sebep olacak ve bu zengin birikimimizin geleceğimizin mimarı olan öğrencilerimiz tarafından özümsenmesine engel olacaktır. Bu anlamda Çarkıt (2019) gerçekleştirdiği araştırmada ders kitaplarının niteliğinin hedef kazanımlara ulaşmada önemli bir faktör olduğunu ifade etmektedir. Kültürel değerlerin aktarımı noktasında da bu görüş anlam kazanmaktadır.

Kültürel mirasın aktarımında birçok kaynak kullanılsa da görüşmeci öğretmenler bu anlamda daha çok kitaplar ve interneti kullandıklarını ifade etmişlerdir. Bunların dışında birincil kaynaklar, geleneksel oyunlar, yöresel numuneler de başvurulan kaynaklar içerisindedir. Bilişim çağını yaşadığımız günümüzde, kültürel mirasımızın aktarımında internet kullanımı oldukça önemli bulunmaktadır. Bu anlamda öğrencilerin somut olmayan kültürel mirasımızı tanıyıp öğrenebilecekleri sanal ortamlar oluşturulması bir zorunluluk olarak görülmektedir. Taş Alicenap (2015)'a göre zengin kültürel birikimimize ait anlatılar güncellenerek varlığını devam ettirmelidir. Çağın ihtiyaçlarına göre yapılacak bu güncellemede internet ve sanal ortamlardan yararlanılmalı, öğrencilerin bu ortamlardan kültürel değerlerimize ilişkin bilgiler edinmeleri ve bu anlamda bir farkındalık kazanmalarının yolu açımalıdır. Bu çerçevede gerek TRT'de hazırlanacak animasyon, çizgi film, kısa film, video ve belgeseller gerek kültürel derinliklerimizden esinlenerek tasarlanacak çocuk oyunları öğrencilerimizin kültürel birikimimizi tanıyıp benimsemeleri adına yararlı olacaktır.

Araştırma sonuçlarına göre öğretmenlerin ortaokul sürecinde öğrencilere kazandırılmasının gerekli olduğunu düşündükleri ve ders kitaplarında yer verilmesini istedikleri başlıca kültürel unsurlar; vatan, millet, bayrak, dil sevgisi, Türk Büyüklerimiz, dini değerlerimiz, bayram geleneklerimiz, mani, ninni, türkü, destan ve efsane gibi edebi türlerimiz, düğün, nişan, kına gecesi vb. adetlerimiz, sofra kültürümüz, Türk misafirperverliği, görgü kurallarımız, geleneksel el sanatlarımız, geleneksel oyunlarımız ve hoşgörü, yardımseverlik, dürüstlük vb. değerlerimizdir. Kültürel mirasımızın öğrencilere kazandırılmasında, yaşayarak öğrenme oldukça önemlidir. Öğretmenler süreçte farklı yöntem ve tekniklere başvurmalı ve öğrencilerin kendilerini rahatça ifade edebilecekleri çoklu öğrenme ortamları oluşturmalıdırlar. 


\section{SONUÇ VE ÖNERILER}

Araştırmada Türkçe öğretmenlerinin kültür aktarımına önem verdikleri, bu amaçla sınıf içi ve sınıf dışı olmak üzere farkı uygulamalar gerçekleştirdikleri buna karşın Türkçe ders kitaplarını kültür aktarımı bağlamında yetersiz buldukları sonuçlarına ulaşılmıştır. Bununla beraber kültür aktarımı sürecinde kitaplar ve internetin öğretmenler tarafından en çok kullanılan kaynaklar olduğu belirlenmiştir. Araştıma sonucunda elde edilen bulgu ve yorumlardan hareketle aşağıdaki önerilerde bulunulabilir:

- Öğretmen eğitiminde kültür aktarımını konu edilen derslere yer verilmeli bu anlamda sadece Türkçe öğretmen adaylarında değil diğer branşlarda eğitim gören öğretmen adaylarında da kültürel mirasımızın gelecek kuşaklara aktarımı konusunda bir farkındalık oluşturulmalıdır.

- Öğretmen ve öğretmen adaylarının yararlanabileceği kuramdan uygulamaya kültür aktarımını konu edinen kitaplar hazırlanmalıdır.

- Kültürel değerler sınıf düzeylerine göre kategorilendirilmeli ve ders kitaplarında kültürel mirasımıza ilişkin metinlere aşamalı bir şekilde yer verilmelidir.

- Öğrencilerin hangi sınıf düzeyinde hangi kültürel mirasımızı kazanacağı ve temel eğitimi bitirdiğinde bu anlamda hangi donanımları edinmiş olacağı önceden planlanmalıdır.

- Internet ve televizyonun kültürel değerlerin aktarımı konusunda etkili bir biçimde kullanılmalı; bu bağlamda gerek TRT gerek EBA'da kültürel mirasımızı konu edinen animasyon, çizgi film, kısa film, video ve belgeseller yayınlanmalıdır.

- Kültürel mirasımızın akratımına yönelik okul içi ve okul dışında gerçekleştirilen faaliyetler okulların internet siteleri ve EBA'da paylaşılarak öğrencilerde bu konuda bir farkındalık oluşturulmalıdır.

- Ortaokul ve liselerde gerçekleştirilen TÜBITAK Bilim Fuarlarına yönelik araştırmalarda kültürel miras unsurlarımız araştırma konusu edilmeli ve öğrencilere bu değerlerimizi araştırmaya yönlendirilmelidir.

\section{KAYNAKÇA}

Aksan, D. (2001). Türkşenin gücü. i̇stanbul: Bilgi Yayınevi.

Aytaçlı, B. (2003). Durum çalışmasına ayrıntılı bir bakış. Adnan Menderes Üniversitesi Eğitim Fakültesi Eğitim Bilimleri Dergisi. 3(1), 1- 9.

Barker, C. (2008). Cultural studies: Theory and practice (3rd ed.). London: Sage Publications.

Bulut, M. ve Orhan, S. (2012). Türkçe-edebiyat ders kitaplarının dil ve kültür aktarımındaki rolü ve önemi üzerine bir inceleme. The Journal of Academic Social Science Studies, 5(8), 297-311.

Cemaloğlu, N. (2011). Veri toplama teknikleri nicel-nitel. A. Tanrı̈̆ğen (Ed) Bilimsel Araştırma Yöntemleri. Ankara: Anı Yayınları.

Çarkıt, C. (2019). 2018 Türkçe dersi öğretim programı çerçevesinde hazırlanan 8. sınıf Türkçe ders kitabının değerlendirilmesi. Elektronik Sosyal Bilimler Dergisi,18(71), 1368-1376.

Demir, A. ve Açık, F. (2011). Türkçenin yabancı dil olarak öğretiminde kültürlerarası yaklaşım ve seçilecek metinlerde bulunması gereken özellikler. TÜBAR -XXX, Güz Sayısı, 51-72.

Denzin, N. K. \& Lincoln, Y. S. (Eds) (1994). Handbook of Qualitative Research. Thousand Oas, CA: Sage Publications.

Deveci, H. (2009). Sosyal bilgiler dersinde kültürden yararlanma: Öğretmen adaylarının kültür portfolyolarının incelenmesi. Elektronik Sosyal Bilimler Dergisi, 8(28), 1-19.

Ekici, M. (2004). Bir sempozyumun ardından: Somut olmayan kültürel mirasın müzelenmesi. Millî Folklor, 16(61), 5-13.

Flyvbjerg, B. (2006). Five misunderstandings about case-study research. Qualitative Inquiry, 12(2), 219-245.

Göçer, A. (2012). Dil-kültür ilişkisi ve etkileşimi üzerine. Türk Dili, 729, 50-57.

Göçer, A. (2013). Türkçe öğretmeni adaylarının dil kültür ilişkisi üzerine görüşleri: Fenomenolojik bir araştırma. Erzincan Üniversitesi Eğitim Fakültesi Dergisi, 15(2), 25-38.

Güfta, H. ve Kan, O. (2011). ilköğretim 7. sınıf Türkçe ders kitaplarının dil ile ilgili kültür ögeleri açısından incelenmesi. Mustafa Kemal Üniversitesi Sosyal Bilimler Enstitüsü Dergisi, 8(15), 239-256.

Güvenç, B. (1994). Insan ve kültür (6. baskı). ìstanbul: Remzi Kitabevi.

Kalfa, M. (2013). Yabancılara Türkçe öğretiminde sözlü kültür unsurlarının kullanımı. Millî Folklor, 97, 167-177.

Kaplan, M. (2001). Türk milletinin kültürel değerleri. Ankara: MEB Yayınları.

Kaplan, M. (2003). Kültür ve dil (16. basım). İstanbul: Dergâh Yayınları.

Kolaç, E. (2009). Somut olmayan kültürel mirası koruma bilinç ve duyarlılık oluşturmada Türkçe eğitiminin önemi. Millî Folklor, 82, $19-31$.

Korkmaz, Z. (1980). İnsan varlı̆̆ından millet ve kültür varlığına uzanan dil. Millî Kültür, 2(2), 15-20.

Melanlıŏ̆lu, D. (2008). Kültür aktarımı açııından Türkçe öğretim programları. Eğitim ve Bilim, 33(150), 64-73.

Oğuz, M. Ö. (2013). Terim olarak somut olmayan kültürel miras. Milli Folklor, 100, 5-13.

Okuyan, H. Y. (2012). Iliköğretim Türkçe ders kitaplarında bir kültür aktarımı aracı olarak kalıp sözlerin kullanımı üzerine bir inceleme. TSA, 16(2), 31-46.

Patton, M. Q. (2014). Nitel araştırma ve değerlendirme yöntemleri. Ankara: Pegem Akademi.

Porzig, W. (1985). Dil denen mucize. Ankara: Kültür ve Turizm Bakanlı̆̆ı Yayınları.

Taş, A., Ç. (2015). Kültürel mirasın çizgi film senaryolarında kullanılması. TÜBAR. XXXVII, 11-26. 
TDK.(2005). Türkçe sözlük (10. basım). Ankara: TDK Yayınları.

Türkmen, N. (2012). Çizgi filmlerin kültür aktarımındaki rolü ve Pepee. CÜ Sosyal Bilimler Dergisi, 36(2), 139-158.

Uyar, Y. (2007). Türkçe öğretiminde kültür aktarımı ve kültürel kimlik geliştirme (Yayımlanmamış yüksek lisans tezi). Gazi Üniversitesi Eğitim Bilimleri Enstitüsü, Ankara.

Ünalan, Ş. (2002). Dil ve kültür. Ankara: Gazi Üniversitesi Basımevi.

Yıldırım, A., ve Şimşek, H. (2016). Nitel araştırma yöntemleri (10. baskı). Ankara: Seçkin Yayıncılık.

Yin, R.K. (2012). Aplications of case study research (3. Edition). USA: Sage Puplications. 